\title{
Modern Social Support Structures: Online Social Networks and their Implications for Social Workers
}

\author{
Kala Chakradhar \\ Victor Raj \\ Arabella Raj
}

\begin{abstract}
Mapping and assessing social networks and the quality of their social support is a valuable intervention strategy for social workers. These networks have now spread onto the digital realm in the form of Online Social Networks (OSNs). This study investigated the nature of social support provided by such networks to their users in a rural mid-South University (USA) and explored parallels with the current understanding of social support in conventional social networks. A web-based survey administered to college students revealed that users of these online networks were predominantly undergraduate first year students, female, single, unemployed and from a variety of academic disciplines. The examination of the components of OSNs appears to mirror those of offline networks. They also seem to complement the effects of each other while contributing to an individual's support system. The paper concludes with critical implications of such online social networking for University students and social workers in practice and education.
\end{abstract}

Keywords: Online social networks; Facebook; social support dimensions; social work practice; PIE perspective

\section{INTRODUCTION}

Social support has been described as "information leading the subject to believe that he is cared for and loved, esteemed and valued, and a member of a network of communication and mutual obligations" including elements like esteem support, emotional support and network support (Cobb, 1976, p. 300). Social support includes the kind of support provided by ties or links - "social networks" - that individuals have to friends/family and such other contacts. Today these forms of support have been consolidated into functional social support and structural support (Hittner \& Swickert, 2001).

The positive role of social support as a moderator of stress and a predictor of good health (physical/mental) has been investigated with diverse populations and repeatedly affirmed in the literature (Brown \& Riley, 2006; Clara, Cox, Enns, Murray \& Torgrudc, 2003; Davidson \& Demaray, 2007). Students transitioning to college life are influenced by the nature and quality of their social support. The entry into, and adjustment to, the university context is a stressful transition, requiring encounters with multiple challenges (Clara et al., 2003; Phinney \& Haas, 2003). Students adapt using various coping

Kala Chakradhar, Ph.D., is an assistant professor in the Department of Social Work, Criminal Justice and Gerontology; Victor Raj, Ph.D., is a professor and department chair of Computer Science and Information Systems; and Arabella Raj, M.S., is a research associate; all at Murray State University, Murray, KY. An earlier version of this paper was presented at the $32^{\text {nd }}$ Annual National Institute on Social Work and Human Services in Rural Areas, July 25-28, 2007, Montgomery, $\mathrm{AL}$

Copyright (C) 2009 Advances in Social Work Vol. 10 No. 2 (Fall 2009), 157-175 
mechanisms that could involve social support - both positive and negative. Technology in the form of telecommunications and the internet has brought in several new factors that impact their support networks.

A whole generation of people, especially adolescents and young adults, is now comfortable socializing, learning, and staying current in this virtual world (Subrahmanyam \& Lin, 2007). This technology has taken people's need to connect with others and propelled them into a world where, with just a few clicks of the computer mouse, they can invite someone to be a "friend" in an online social network (OSN). Friendships are initiated easily without the benefit/drawback of a face-to-face introduction.

The purpose of this exploratory research initiative was three-fold: (1) to investigate the online social networking phenomenon in a rural mid-south university and explore the characteristics of OSN users in order to arrive at a profile specific to such populations; (2) to explore the nature of the social support provided by these networks in terms of its functional, structural and perceptual dimensions; and (3) to examine the expanded scope for social work practitioners with OSNs, given the key role that social workers play in understanding and working with offline social networks.

\section{LITERATURE REVIEW}

Studying and understanding social networks of individuals and families by social workers has set the stage for assessing available social supports and planning appropriate intervention for enhancing individual and family functioning (MacNeil, Stewart \& Kaufman, 2000). Chronister, Johnson and Berven (2006) conceptualize social support through five theoretical models: stress-buffering, main-effect, support mobilization, perceived support, and support deterioration. They further characterize 'social support' as a multidimensional concept consisting of structural, functional, and perceptual dimensions. Structural support represents the quantitative aspects of social support like network size, frequency of contacts, density and composition, while functional support characterizes the degree to which an individual believes that help is available and therefore is seen as a qualitative measure. While structural support also includes social network resources and affiliations, functional support includes emotional, instrumental and informational forms of support. The perceptual dimension includes a more subjective measure relating to the satisfaction experienced by individuals in and through their support networks. They also note that not all social support can be assumed to be positive and beneficial.

Social support is an important predictor of health (mental and physical well-being) with low social support being associated with higher rates of loneliness among college students. Perceived social support serves as a protective factor against mental health problems (Clara et al., 2003). Larose and Boivin's (1998) review infers that first-year students experienced increased stress during their adjustment into college. This is evidenced by low social and emotional adjustment measures compared to junior or senior students, increased feelings of loneliness, report of negative life events and poor academic adjustment. Borsari and Carey (2006) consider formation of friendships to be 
crucial for college students in acquiring and establishing a psychological identity in this period of 'major developmental transition.' These friendships with contemporaries facilitate social interactions and opportunities to emulate through role models (p. 361). These connections are sought through associations that support their social identity like ethnicity, social roles (athletes), membership in organizations (sorority) (Weisz \& Wood, 2000), 'social smoking' (Waters, Harris, Hall, Nazir \& Waigandt, 2006), or alcohol use (Borsari \& Carey, 2006). According to Liu (2007) in today's text-heavy online world, identity expression and establishing social links is through creating a social network profile of oneself on online networks. Favorable social networks contribute to successful completion of academic careers (Borsari \& Carey, 2006; Weckwerth \& Flynn, 2006; Wilcox, Winn \& Fyvie-Gauld, 2005).

Highlighting how computer technology and internet use are impacting social relationships in different age groups, Gonchar and Adams (2000) demonstrate a need to explore this aspect of an individual's social system. They recommend inclusion of the online environment in the assessment of client support systems when using the person-inenvironment (PIE) approach. Of particular concern for this study are network services like MySpace and Facebook which have been reported to be catering to the academic community, primarily undergraduate populations (Golder, Wilkinson \& Huberman, 2006). According to Golder et al. (2006, para 8) a "social network website describes a class of web services that invites users to create an online profile of themselves, most commonly...a photograph, a listing of vital statistics (name, location ... occupation) and interests. Most crucially, these services are focused on allowing users to list other users as 'friends,' thereby linking their pages to one another and publicly demonstrating their connection...." A substantial number of these "friendship" sites are structured to "delineate and build on relationships that members have with each other by virtue of their being part of that (geographic) community" (Barsky \& Purdon, 2006, p. 65).

In just two to three years of operation (at the time of this survey), these OSNs had amassed between 10 million (facebook) and 80 million (mySpace) users in the United States. These networks provide opportunities for individuals to create online content, post photographs and video clips, share music, and create and maintain friendships (Barsky \& Purdon, 2006; Lorenzo \& Dziuben, 2006; Oblinger \& Hawkins, 2006). These OSNs have opened outlets for "adolescent expression," information sharing, and skill building, both social and technical (Bradley, 2005). Campbell, Cumming and Hughes' (2006) combined online/offline survey of undergraduate students who were regular internet users, showed that for the "socially fearful" the internet offers a low risk approach to socializing and a preliminary form of rehearsing for future face-to-face encounters. However, the risk of social isolation and loneliness is also present (Campbell et al., 2006).

A nationwide telephone survey in the U.S. in Oct/Nov. 2006 of 935, 12-17 year olds (Lenhart \& Madden, 2007) yielded data revealing a predominance of girls among members of social networking sites. Fifty percent of the sample reported using these sites with membership in MySpace, exceeding that of Facebook significantly (12:1). The motivating factors included making new friends and dating opportunities (Lenhart \& Madden, 2007). In addition De Gagne and Wolk (2006) found in their survey of a liberal arts college in Massachusetts $(n=565)$ that Facebook/MySpace helps students retain 
friends (alumni) and seek academic help. These "virtual communities" hold potential for boosting psychological health through substituting for face-to-face communities and even relief giving outlets like "e-mourning" (Andreatos, 2006). Strong connections have also been drawn to the social capital gains that Facebook users stand to acquire, apart from a boost to individual self-esteem (Ellison, Steinfield \& Lampe, 2006; 2007).

The flip side of OSNs has been privacy concerns, risks of defamation, intellectual property ownership (with indiscriminate downloading and information transfer) and deceptive identities. Faculty, administrators, and university presidents sharing Facebook membership has led to some online behavior monitoring (Mitrano, 2006). Prospective employers have been known to use this online medium as a resource for background checks (Oblinger \& Hawkins, 2006). The realization of this dubious outcome of empowerment and vulnerability has led to educational institutions creating and implementing policies to help in monitoring such online activity on campuses nationwide.

As cited by De Gagne and Wolk (2006), the effects of this technology may not be uniform across university campuses and may depend on "institutional affluence, student ability, socioeconomic status, and accessibility" (p. 2), to name a few. An investigation of the effects of this form of OSN in a diverse university campus (rural, non-traditional, and international students) (Factbook, 2005-2006) hopes to lead to knowledge of this phenomenon and its possible social support dimensions.

Though there have been reports on use of online therapy in cyberspace as a form of social work intervention (Menon \& Miller-Cribbs, 2003) there are no known studies from the social work profession on such online networks and their role. The available literature includes a large number of in-house reports, student papers and limited scholarly work from University populations in the Eastern United States, primarily urban campuses (De Gagne \& Wolk, 2006; Govani \& Pashley, 2005; Ellison et al., 2006; Liu, 2007)— populations that differ from this rural campus. The reported research is from disciplines like telecommunications (Ellison et al., 2007), media studies (Liu, 2007), communication studies and sociology (Hargittai, 2007). From the social work perspective, can this form of networking be a potential adjunct or even a substitute for conventional offline social supports? Does this form of networking have the potential to create a favorable and socially positive experience and does it carry the risk of ill effects?

For professions like social work, OSNs raise questions about the quality of support they provide. Although strong connections have been drawn to the social capital gains that Facebook users stand to acquire at the macro level (Ellison et al., 2006; 2007), this research focuses on the social support gains at the micro level. The answers that surface from this research could point to the inclusion of OSNs in PIE (Person-In-Environment) assessments using the ecological perspective for social workers and use in campus wellness programs (Myers \& Mobley, 2004; Wells, Mitchell, Finkelhor \& Blease, 2006). Furman, Collins and Swanson (2003), through the use of illustrative case examples, have demonstrated the importance of helping clients develop friendships as a form of intervention in social work practice. 
Towards this end, an exploratory study was designed to identify characteristics of the typical online network user in a rural university and the nature of the social support provided by these networks. The results were used to derive implications for the social work practitioner in rural settings.

\section{METHODS}

After approval from the Institutional Review Board (IRB), a list of all the students enrolled in a rural university of about 10,000 students for spring 2007 was obtained from the Registrar's office. An e-mail (with a link to the web survey) was sent to a proportionate stratified random sample (based on academic classification-First year, Sophomore, Junior, Senior, Graduate and Irregular that matched their distribution in the university population: N=9044. Spring 2007 semester) of 400 students inviting them to participate in the web-based survey. The survey ensured voluntary participation and anonymity. Responses from 82 (a 20.5\% response rate) were returned. Earlier web-based surveys at this university had a response rate of $18-20 \%$ in spite of incentives and larger sample size (personal communication, Judy Lyle, March 21, 2008). This experience was consistent with online response rate limitations reported in the literature, ranging from $20 \%$ to $70 \%$ with an average response rate of $36 \%$ (Kaplowitz, Hadlock \& Levine, 2004).

The distribution of participants closely reflected the population of interest with respect to academic classification $\left(\chi^{2}=8.25, p=0.15\right)$ and gender $\left(\chi^{2}=0.02, p=0.89\right)$ thereby reinforcing the representative nature of the sample. Though a sampling frame was available and sample representativeness ensured and established, issues of "churn," namely holding multiple email addresses, changing providers, or equipment malfunction (Sheehan, 2001), could have contributed to this response rate.

\section{Survey Measures}

The survey gathered data on functional and structural support as captured in usage habits, preferred features/services, benefits experienced, and technical competence, as well as awareness of issues relating to privacy and security. Though standardized social support measures are available for offline social support assessment, they have been found to have limitations in addressing all support dimensions in one tool (Chronister et al., 2006). Given the unique nature of the OSN and insufficient knowledge of its characteristics, it was necessary to develop a set of questions specific to the nature of this phenomenon using the available literature (Campbell et al., 2006; De Gagne \& Wolk, 2006; Ellison et al., 2006; Golder et al., 2006; Govani \& Pashley, 2005).

Demographics: This included independent variables like gender, marital status, age, employment status, class load, academic classification, distance from campus, dependents at home, and academic major.

Functional: Functional dimension of social support measures included questions on personal data (profile) posted (birthday, contact information, pictures, etc.), reasons for membership and non-membership, and preferred features of the OSN. Likert-type scales were also used to elicit responses on use and benefits of OSNs (instrumental, informational and emotional support). 
Structural: To address this dimension, the survey gathered data on the preferred OSNs, duration of membership, frequency of signing in, length of time spent at each login, day of week logged in, and number of friends in their network

Perceptual: Likert scales were used to elicit responses as evidence of their perception of positive and negative effects of OSNs: hurt grades, prevented normal social interaction, raised objections from friends or family, unpleasant experience, wasting time, felt less anxious, gave comfort with transitions, helped cope with stress, etc.

The online survey tool allowed the researchers to automatically direct respondents according to their membership in OSNs. Non-users were taken directly to questions about their perception of OSNs and demographics. Users were probed further about their participation and experience in OSNs. The data were analyzed using descriptive statistical measures and contingency tables.

Sample Profile: The sample included 59\% females and 38\% males with 3\% not indicating gender $(\mathrm{n}=82)$. The respondents identified themselves as first year $(15)$, second year (14), third year (12), fourth year (23) and others (6). The average age of the respondents was $26(\mathrm{SD}=8.84)$. Unlike other reported studies with university populations (Govani \& Pashley, 2005; Ellison et al., 2006), this sample exhibited higher dispersion with respect to age due to the presence of non-traditional and graduate students. Of the 82 respondents, about $60 \%$ were single, $25 \%$ were married and $20 \%$ had children less than 18 years of age living with them. About $63 \%$ were employed, with about 30\% working 10-20 hours a week. These variables (marital status, employment status, dependents) have not been included in earlier research nor has their relationship to the use of OSNs been examined. With about 70\% residing within 3 hours' driving time from campus, a sizable number of students were not too far from their existing offline networks.

To investigate whether the availability of free time encouraged the use of online social networks, data were collected on group affiliation, academic load and choice of academic major. Of the 82 respondents, about 37\% reported being affiliated with religious groups, $22 \%$ with athletics, $13 \%$ with fraternities or sororities, and another $11 \%$ with art societies or other groups. About $26 \%$ had no such affiliations. The number of credit hours taken ranged from 1-19 with an average of 13 (SD=4). The students represented diverse areas of study with no clear dominance of any single academic major.

\section{FINDINGS AND DISCUSSION}

The survey pointed to several distinct characteristics of participants of online social networks. The following discussion addresses demographic characteristics and social support dimensions (functional, structural and perceptual) of OSNs. Differences between the genders and academic classification were also observed and are discussed.

\section{User Characteristics}

In keeping with the study's core objective, a substantial section of the survey focused on the students' use of OSNs (such as MySpace and Facebook), reasons for use, and 
experiences as a result of this use. Ninety-nine percent of the respondents were aware of such networks while seventy percent (58 of 82) were using such networks. About $47 \%$ of the users were using more than one OSN including Facebook, MySpace, Xanga, Hi5, Wayn, Bebo, Live journal, Orkut and Inner circle. Facebook and MySpace appeared to be the most popular (47\% and $43 \%$ respectively) with $35 \%$ using Facebook most of the time. For this survey, the participants were asked to respond using a preferred OSN as their frame of reference.

Female users constituted a higher proportion (55\%) than males $(41 \%)$, with the average age of users being 23. All first-year students in the sample and a majority of second year $(86 \%)$ and third year $(67 \%)$ students were users. A sizable number were single $(71 \%)$, worked less than 20 hours a week $(51 \%)$ and were affiliated with various non-academic groups (79\%).

Structural Support: The typical user had to "login" to access such networks. Once logged in, the user can interact with other "friends," invite others to become friends, and join or start groups with the click of a button. These may be construed as quantitative social support elements for the online community.

Almost $60 \%$ logged on to these sites several times a day. Fifty-five percent spent less than 10 minutes during each login. Most (65.5\%) accessed these sites throughout the week while about $30 \%$ did so only on weekdays, possibly indicating that their usual weekend activities were not affected. Almost $75 \%$ of the participants had their accounts for more than a year and reported having links to more than a hundred friends. About $90 \%$ sought and added close friends from college and high school to the OSN while $45 \%$ accepted friendship from those not known through such contexts. Sixty-five percent of the respondents accepted people as friends only after meeting them face-to-face while $71 \%$ seemed comfortable accepting acquaintances as friends.

It therefore appears that through frequent visits, spending time at each logged-in session and the building of networks of friends, users of OSNs do seem to experience a form of structural support similar to offline networks.

Functional Support: Functional support elements address the purpose served by the networks for the individual. In OSNs, most used them for posting of pictures $(95 \%)$, birthdays (91\%), and interests (88\%). About 55\% posted information about their religion. A large portion of the users did not post their contact information and cell phone numbers (74\%). It could be inferred that students in this rural population are cautious about seeking support in an OSN. The most compelling reasons for creating an OSN account were friends' recommendations, a need to be connected, sharing information and making new friends. A very small number (5\%) also saw this OSN as providing opportunities to find dates. None of the users in this sample used this medium for job searches.

Like offline networks, functional support in OSNs is derived from sharing information about themselves and learning about others who also post such information. The OSNs also serve the important function of relieving boredom (84\%), fighting loneliness $(21 \%)$ or seeking help for a problem or a crisis (5-12\%). They also used these as a tool to "spread the word" and draw people to events or other group activities. 
Perceptual: The perceptual support dimension looks at the individual's perception of the positive and negative effects of social networks and the kind of support experienced by that individual. About $70 \%$ had rejected or ignored requests for friendship primarily because of not wanting to associate with the individual seeking friendship. Other specific reasons given by the respondents were that they did not know them or did not like what they saw posted. One respondent noted that a contact's face-to-face indifferent behavior had helped in the decision to remove the Facebook contact as a "friend." Some highlights from the data suggest that about $40 \%$ of the users felt less anxious communicating with people online than they did face-to-face. About $62 \%$ felt that the use of these OSNs did not affect their grades while $22 \%$ felt that their grades were hurt. Eighty-eight percent of the respondents noted that their participation in OSNs did not result in objections from faculty or family. This statistic may not remain the same as this activity becomes widespread and is perceived as disruptive.

Respondents were also asked about the negative effects experienced due to their sharing of personal information. Members do not have control over pictures of themselves posted by others in their own albums and linked ("tagged"). Twenty-six percent reported that they had some form of unpleasant experience including loss of a potential job and conflicts in intimate relationships. At best this online interaction could be opening doors for new friendships, at worst it could be embarrassing and terminate friendships. Given the openness of OSNs, the potential to cause harm for other users by manipulating such information may be viewed as a form of bullying or hazing, behaviors that exist in offline networks as well.

It is natural to assess potential relationships by observing the individual's behavior prior to developing or nurturing them. In OSNs, this is accomplished by using the built-in safety and privacy features of the OSNs judiciously. About $70 \%$ of the users had reviewed the OSN's privacy policy and $78 \%$ had tried to change the setting to ensure a secure and safe operation. However there were $20 \%$ who had not.

Having examined the nature of social support in OSNs, the following section explores the effects on sub-groups within the sample, especially academic status and gender.

\section{Sub-group Characteristics}

Academic standing effects: Reviewing the premise that college-going years are a developmental challenge to many, especially first and second-year students, an analysis of the differences between first year/sophomore (underclass) and junior/senior (upperclass) was made with respect to these social support characteristics.

As shown in Figure 1, distinct trends and differences were observed between these groups on some of the support-reflecting characteristics. It appears that more underclass students perceive benefits from OSNs than do juniors \& seniors. This measure of the perceptual support dimension included Likert-type responses to multiple items where "strongly agree" and "agree" were combined for the values shown in Table 1. The measures showed a statistically significant association between academic standing and 
some elements of the perceptual dimension. The underclass students perceived greater benefits in larger numbers from OSNs than upperclass students.

Figure 1. Perceived Benefits of OSNs

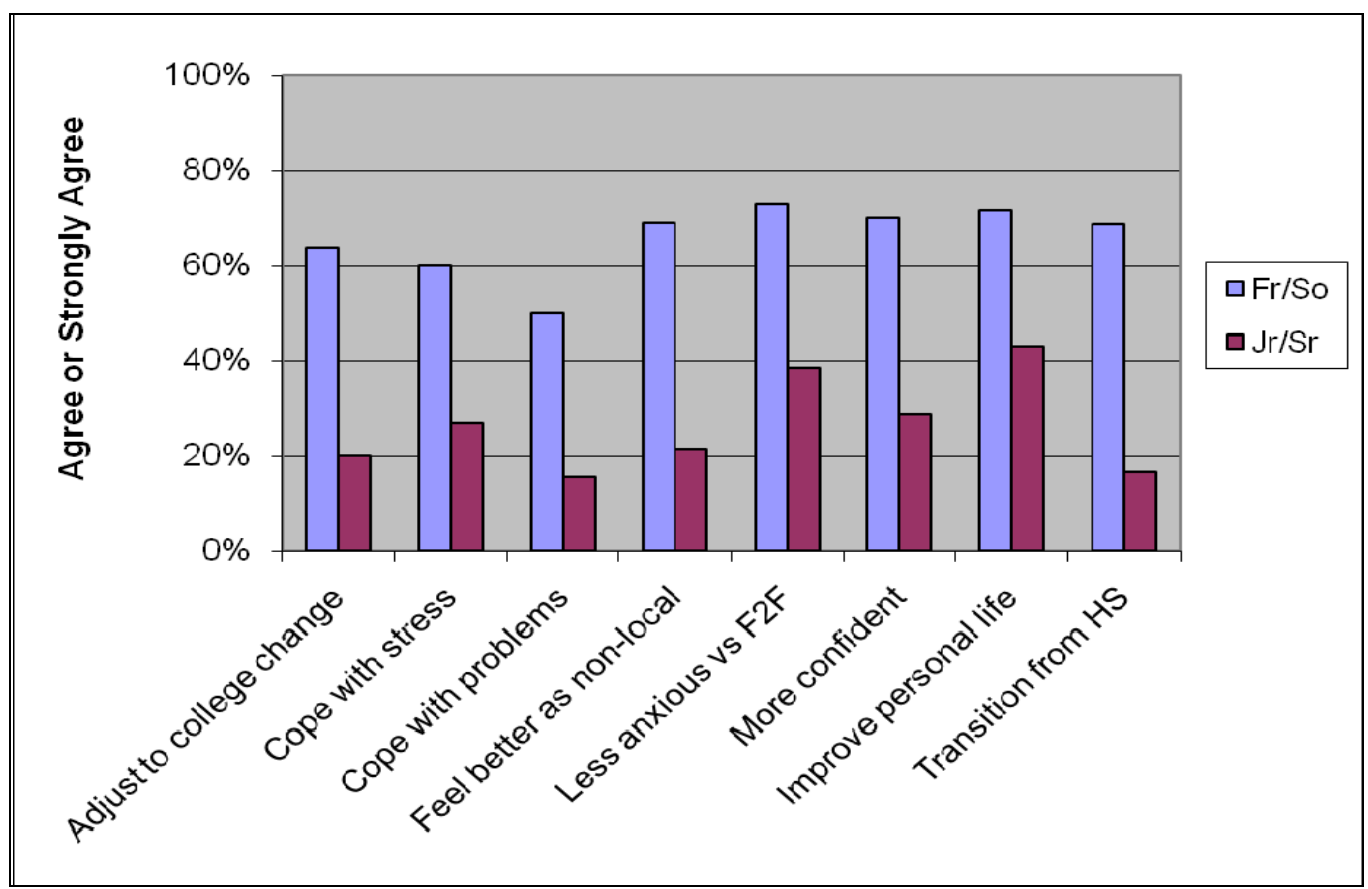

On the other hand, the not-so-beneficial outcomes were also experienced by the younger group, though the association was not statistically significant (Figure 2). It is imperative that social workers be aware of the benefits and dangers of OSNs as experienced by underclass students who are adapting to the transition from the school environment to the college environment.

Table 1. Subgroup Differences along Perceptual Dimension

\begin{tabular}{lcccc}
\hline Measure & Female \% & Male \% & FR/SO \% & JR/SR \% \\
\hline Cope with everyday stresses & 58 & 42 & 75 & $25^{*}$ \\
Cope with personal problems & 62 & 38 & 72 & $18^{*}$ \\
Feel better since I am not from here & 73 & 27 & 79 & $21^{*}$ \\
$\begin{array}{l}\text { Feel less anxious asking /telling/ } \\
\text { sharing things with people than F2F }\end{array}$ & 57 & $43^{*}$ & 76 & $24^{*}$ \\
Forget problems & 36 & 64 & 90 & $10^{*}$ \\
\hline$\chi^{2}, p<0.05$ & & & & \\
\hline
\end{tabular}


Figure 2: $\quad$ Perceived Negative Effects of OSNs by Academic Standing.

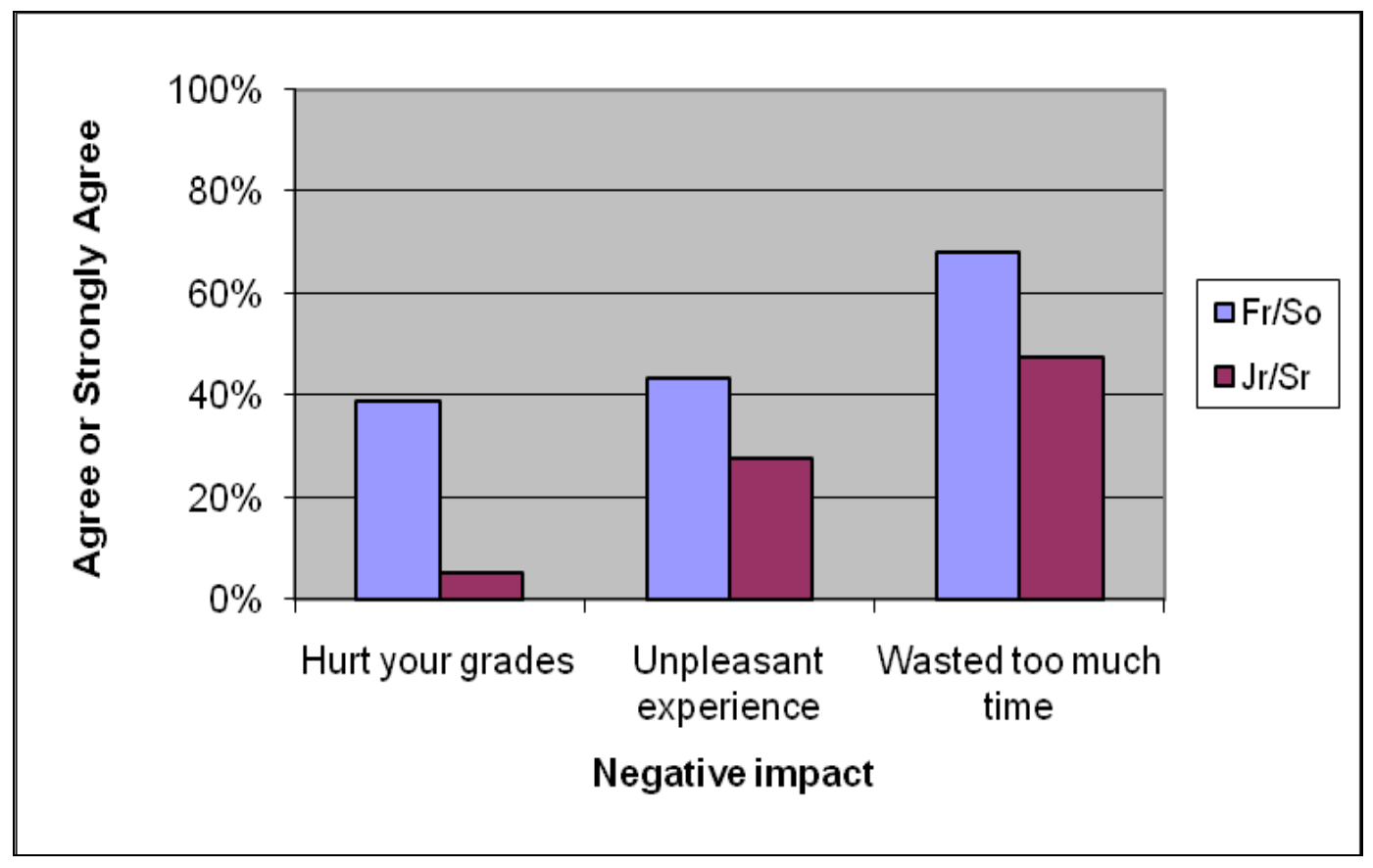

Table 2. Subgroup Differences on the Functional Dimension

\begin{tabular}{|c|c|c|c|c|}
\hline Measure & Female \% & Male \% & FR/SO \% & JR/SR \% \\
\hline Friend recommended & 63 & 37 & 61 & 39 \\
\hline Everyone I know is on this & 59 & 41 & 53 & 47 \\
\hline Ability to make new friends & 57 & 43 & 69 & 31 \\
\hline $\begin{array}{l}\text { Used when needing to share a } \\
\text { problem }\end{array}$ & 75 & 25 & 33 & 67 \\
\hline Used when needing help in a crisis & 67 & 33 & 50 & 50 \\
\hline $\begin{array}{l}\text { Learn more about others in your } \\
\text { class }\end{array}$ & 64 & 36 & 56 & 44 \\
\hline $\begin{array}{l}\text { Learn more about other people } \\
\text { living close by }\end{array}$ & 59 & 41 & 63 & 36 \\
\hline $\begin{array}{l}\text { See if you wanted to associate with } \\
\text { someone or not }\end{array}$ & 42 & 58 & 59 & 41 \\
\hline$\chi^{2}, p>0.05$ & & & & \\
\hline
\end{tabular}


With regard to the functional dimension both groups' membership in OSNs served the function of being able to discreetly assess people they met in their classes or those who lived close to them in order to make decisions about continued networking. Though the data points to some differences in the subgroups, they are not statistically significant (see Table 2). The differences changed direction for only one item, viz., "used when needing to share a problem." Some possible explanations for this reversal: (1) the younger students are reluctant to share their problems because they are still testing their social network and/or (2) the older group has an established OSN that facilitates problem sharing.

Figure 3: $\quad$ Differences in Time Spent per Login by Academic Standing

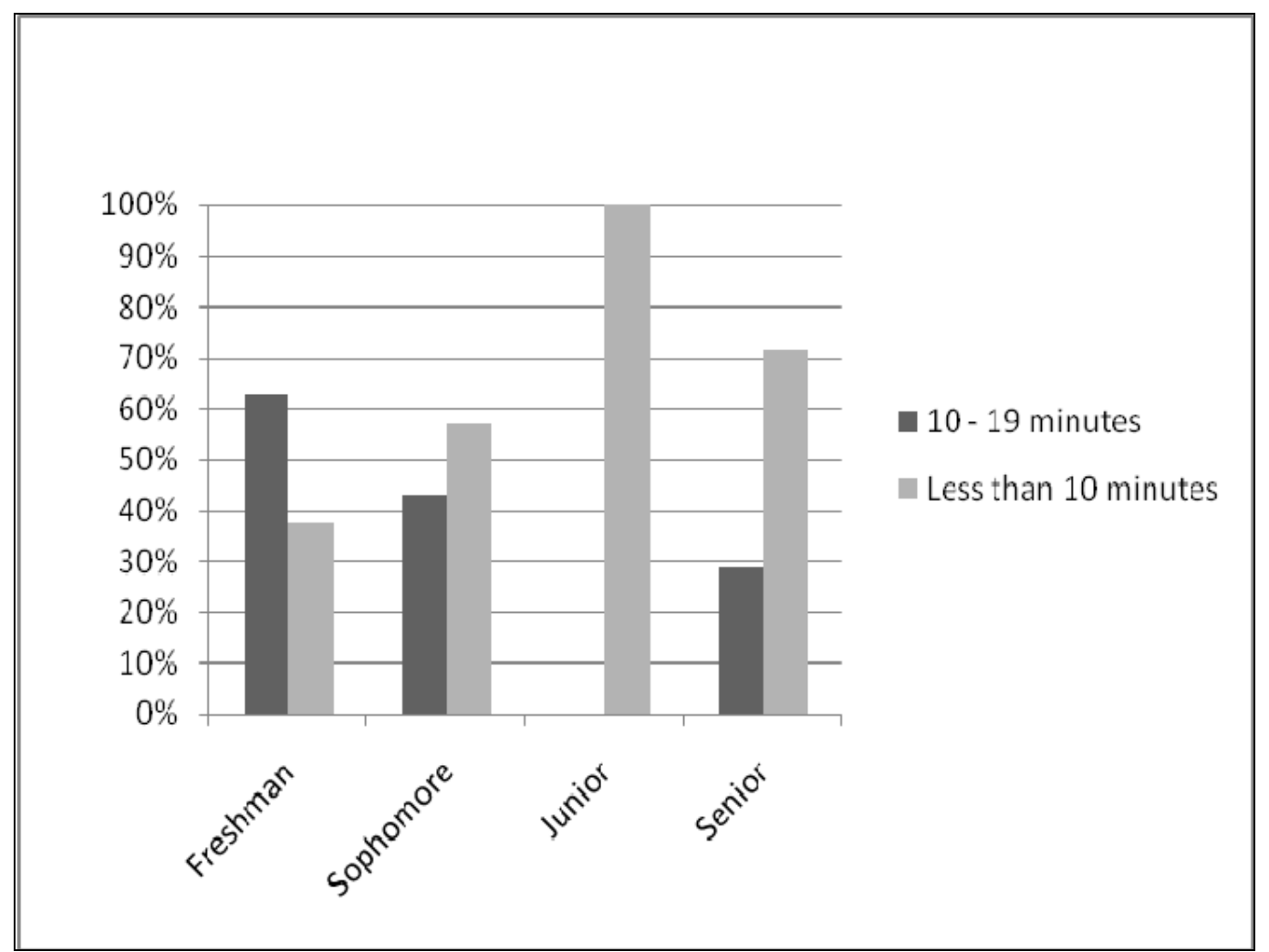

Gender effects: As in offline networks, each gender approached these OSNs differently. Though proportionately more females perceived greater benefits, more males seemed to use OSNs to "forget problems" (see Table 1). On the perceptual dimension items, females were more likely than males to report feeling "less anxious asking /telling/ sharing things with people than face-to-face" $\left(\chi^{2}, p<0.05\right)$.

A similar pattern is observed with respect to the functional dimension with no observed statistical significance $\left(\chi^{2}, p>0.05\right)$. However more males seem to use OSNs "to see if they wanted to associate with someone" (see Table 2). They also used them to 
affiliate with like-minded individuals in larger numbers than females. The genders also differed on use of OSN features related to posting birthdays, pictures and interests, possibly a form of seeking emotional support through self-disclosure (Table 3). However, only a small number of males were using these networks to search for dates $(n=3)$.

Table 3. Gender Preference for OSN Features

\begin{tabular}{lcc}
\hline Measure & Female \% & Male \% \\
\hline Birthday included & 60 & 40 \\
Interests & 53 & 47 \\
Political views & 67 & 33 \\
Posting pictures & 67 & 33 \\
\hline$\chi^{2}, p>0.05$ & & \\
\hline
\end{tabular}

As shown in Table 4, significantly more women than men were open to accepting acquaintances as friends for their OSNs $\left(\chi^{2}, p<0.05\right)$. Although further probing questions could have added clarity, this behavior may have been motivated or encouraged by friends, both offline and online. Though statistically insignificant, female users (56\%; $\mathrm{n}=45$ ) changed their privacy settings and appeared to be more cautious than males.

Table 4. Differences in Subgroups along Structural Dimension.

\begin{tabular}{lcccc}
\hline Measure & Female \% & Male \% & FR/SO \% & JR/SR \% \\
\hline $\begin{array}{l}\text { Logged in several times a day } \\
\text { Invite close friends not known }\end{array}$ & 61 & 39 & 60 & 40 \\
through High School and college & 58 & 42 & 71 & $29^{*}$ \\
Invite acquaintances & 63 & 33 & 62 & 38 \\
Accept acquaintances as friends & 69 & $31^{* *}$ & 61 & 39 \\
$\begin{array}{l}\text { Accept people you didn't meet } \\
\text { F2F as friends }\end{array}$ & 63 & 37 & 56 & 44 \\
$* \chi^{2}, \mathrm{p}<0.05 ; * * \chi^{2}, \mathrm{p}<0.01$ & & & & \\
\hline
\end{tabular}

As noted by researchers, gender (in conventional networks) "moderates the relationship between stress, social support and health" with favorable effects only for females (Hale, Hannum \& Espelage, 2005, p. 277). In peer relationships, men are less likely to confide, express vulnerability, demonstrate affection or discuss personal issues. Intimacy through social support is activity-based in men while it is accomplished through self-disclosure in women. Women are also seen to receive and give more emotional support through their peer relationships than men (Borsari \& Carey, 2006). 


\section{Distinction between Users and Non-Users}

Defining "non-users" as those who are aware of OSNs but did not create an account on any of these networks, this study explored their reasons for eschewing this activity. A little less than half of the non-users $(n=23)$ were not interested in OSNs. A fifth of them saw this as restricting their other activities and about a tenth saw this as inappropriate for their age (older, non-traditional). Another one-tenth preferred other means of communication like phone, e-mail, and face-to-face conversation. One respondent's quip was that "they [OSNs] were [a] breeding ground for gossip and smut.... I am a private person who does not like to broadcast [my]...business."

Finally, some comparisons were drawn between users and non-users with regard to socio-demographic characteristics (Table 5). There was a higher representation of females in both groups (users: $55 \%$ to $41 \%, \mathrm{n}=58$; and non-users: $65 \%$ to $30 \%$; $n=23$ ). The average age of the non-users was 38 years while it was 23 years for the users. Of the non-users, $61 \%$ were married compared to users $(76 \%)$ who were mostly single or divorced $/$ separated $\left(\chi^{2}=23.44, \mathrm{df}=2, p<0.05\right)$.

Taking academic classification into consideration, all first-year students in this sample were users; sophomores and juniors also had a higher representation of users. The distribution among seniors was spread evenly. However, the pattern reversed among graduate and post baccalaureate students with a higher number being non-users.

There was no statistically significant association between number of credit hours a student was taking (less than 12 credits vs. more than 12) and use of this OSN ( $\chi 2=3.57$, $\mathrm{df}=1, p>0.05)$. No significant association was observed between employment status and use of OSNs, although OSN users were more likely to report working less than 20 hours a week $\left(\chi^{2}=11.20, \mathrm{df}=1, p<0.05\right)$. A larger number of the users had affiliations to various groups (athletics, sorority, fraternity, etc); that is, their usual social support structures were not abandoned/ ignored. A larger percentage of non-users reported no affiliations (39.13\%) compared to users $(20.69 \%)$. This difference could be due to a combination of age and family conditions as well as personal preference.

Table 5. Characteristics of OSN Users/ Nonusers

\begin{tabular}{|c|c|c|}
\hline Characteristic & Users & Non-Users \\
\hline Average age & 23 & 38 \\
\hline Marital status* & Mostly single & More married than single \\
\hline Academic classification & All first years were users & $\begin{array}{l}\text { Mostly post-baccalaureate } \\
\text { no freshmen }\end{array}$ \\
\hline Hours at work* & Less than 20 a week & More than 20 a week \\
\hline Affiliation & Various traditional groups & No affiliation \\
\hline
\end{tabular}


These observations on non-users are unique to this study. Other studies that investigated users (members) versus non-users (non-members) had very few non-users for comparison and were only able to report that non-users were older (Ellison et al., 2006; 2007; Hargittai, 2007).

The analyses of the social support dimensions-structural, functional and perceptual-in OSNs reveal a striking parallel to dimensions used in offline social support assessments. That is, we can use the same framework of understanding used in offline networks to understand OSNs and their impact on users. The overall purposes served by these OSNs indicate their use as a medium to socialize and connect. The frequency with which people log on to OSNs and the time spent reflects the time and effort invested in strengthening and maintaining these digital relationships (Golder et al., 2006). Consistent with other studies (Ellison et al., 2006) another purpose served by these OSNs was giving the users something to do when idle, a relatively harmless activity. Consequently, this activity was also perceived as a waste of time. However, these networks facilitate a form of socializing for some, which is less anxiety-provoking than face-to-face interaction. The distinct patterns observed in the underclass and upperclass student experiences lend considerable support to a possible stress-buffering role of these networks in their beginning years of college (Figure 1).

The data also reflect a need for caution in time spent in these interactions that might hinder the academic and/or social experience. Some distinctions observed between the genders validate observations made by other researchers with respect to dynamics of peer associations in offline situations. Respondents' use of discretion in screening people in their network based on their own individual appraisals and ongoing experience is a reflection of the dynamic that is true of face-to-face interactions as well. Although such networks create virtual communities, the tough lessons learned through some negative experiences do re-create the real world of stresses experienced in face-to-face social situations.

\section{CONCLUSIONS AND IMPLICATIONS}

The three-fold purpose of this exploratory study was to (1) arrive at a profile of the typical OSN user in a rural university, (2) identify the online parallels of offline social support dimensions and (3) to examine the expanded scope for social work practitioners with OSNs, given social workers' key role in understanding and working with offline social networks.

This exploratory effort revealed a definitive profile of users of online social networks at this rural university: an undergraduate first year (FR), female, younger in age, single, unemployed, and from diverse academic disciplines. Though the data reveal no clear repercussions on academic performance yet, use of these sites for social networking is seen by users as making considerable demands on time. Those who chose not to participate in such networks did so because of a lack of time. Finally the feedback on its impact does not reveal overwhelming support for using OSNs. In fact, at least half the users saw this type of social networking as fading over time. 
In examining the parallels with social support dimensions in the offline environment, it was possible to conceptualize and operationalize similar dimensions in the online environment. This preliminary investigation enabled delineation of the structural, functional, and perceptual elements of online social networking with some overlap. Further research should help validate these observations and add more clarity to these dimensions. The examination of the components within these dimensions appears to mirror those in offline networks. However, what is unusual is that these online networks of individual students exist in addition to their offline networks. They appear to complement each other while contributing to an individual's support system. Thus, OSNs appear to serve an adjunctive function in helping (especially) underclass students acclimatize to the college environment. By extension, colleges may want to consider OSNs as retention mechanisms.

With these explanations in place this research has some direct implications for social workers as practitioners. Apart from being aware of this social trend and its effects, it asks for an inclusion of the online environment as an assessment component, especially with school and college populations. Planning for assessment should include asking questions about membership in these networks and the nature of support experiences, both favorable and unfavorable. Undergraduate populations, particularly females and single individuals in the first two years of college, appear to be a group that may need attention. Anecdotal evidence from the sample university reveals that during new student orientations recommendations for Facebook memberships are made to incoming students as a way of encouraging networking.

The online environment is thus another system to review and evaluate when practitioners use the PIE (Person- In- Environment) approach for social system support assessment. Training for social work practitioners must include assessment and intervention techniques for dealing with internet-related issues and conflicts (Gonchar \& Adams, 2000; Wells, 2006; Wells et al., 2006). For others, practitioners may want to recommend that their clients explore such online associations to supplement their possibly weak offline networks.

From a broader perspective, Universities should consider encouraging faculty and administrators to become members of OSNs. This has the dual benefit of opening avenues of socialization outside the classroom with current students and facilitating the maintenance of ties with alumni in a safe and cost-efficient manner. It may also be necessary and prudent for administrators to scan OSN activity of potential employees and students, for example, to limit liability and promote safe practices.

As an exploratory effort, the study has its share of limitations. Apart from the weak response rate some of the questions framed seemed to be ambiguous and may have affected the nature of responses. Though the university's international population and out-of-state students were potential targets, they could not be singled out due to IRB constraints. These groups may be targeted for a separate study in the future. Regardless of its limitations, the value of the study is not greatly diminished and the relevance to practitioners is evident. 


\section{References}

Andreatos, A. (2006). Informal learning at virtual communities. Paper presented at the First International Conference on Virtual Learning. Retrieved December 21, 2006 from http://fmi.unibuc.ro/cniv/2006/disc/icvl/documente/pdf/met/3 andreatos.pdf.

Barsky, E., \& Purdon, M. (2006). Introducing Web 2.0: Social networking and social bookmarking for health librarians. Journal of the Canadian Libraries Association, 27(3), 65-67.

Borsari, B., \& Carey, K. B. (2006). How the quality of peer relationships influences college alcohol use. Drug and Alcohol Review, 25(4), 361-370.

Bradley, K. (2005). Internet Lives: Social context and moral domain in adolescent development. New Directions for Youth Development, 2005(108), 57-76.

Brown, V. L., \& Riley, M. A. (2006). Social support, drug use and employment among low-income women. The American Journal of Drug and Alcohol Abuse, 31, 203-223.

Campbell, A. J., Cumming, S. R., \& Hughes, I. (2006). Internet use by the socially fearful: Addiction or therapy. Cyberpsychology \& Behavior, 9(1), 69-81.

Chronister, J. A., Johnson, E. K., \& Berven, N. L. (2006). Measuring social support in rehabilitation. Disability and Rehabilitation, 28(2), 75-84.

Clara, I. P., Cox, B. J., Enns, M. W., Murray, L. T., \& Torgrudc, L. J. (2003). Confirmatory factor analysis of the multi-dimensional scale of perceived social support in clinically distressed and student samples. Journal of Personality Assessment, 81(3), 265-270.

Cobb, S. (1976). Social support as a moderator of life stress. Psychosomatic Medicine, 38(5), 300-314.

Davidson, L. M., \& Demaray, M. K. (2007). Social support as a moderator between victimization and internalizing-externalizing distress from bullying. School Psychology Review, 36(3), 383-405.

De Gagne, M., \& Wolk, R. M. (2006). Unwired: Student use of technology in the ubiquitous computing world, Information Systems Education Journal, 5(13), 3-14.

Ellison, N., Steinfield, C., \& Lampe, C. (2006, June). Spatially bounded online social networks and social capital: The role of Facebook. Paper presented at the Annual Conference of the International Communication Association (ICA), Dresden, Germany. Retrieved December 21, 2006 from http://msu.edu/ nellison/Facebook ICA 2006.pdf.

Ellison, N. B., Steinfield, C., \& Lampe, C. (2007). The benefits of Facebook "friends:" Social capital and college students' use of online social network sites. Journal of Computer-Mediated Communication, 12(4), article 1. Retrieved Feb 1, 2007 from http://jcmc.indiana.edu/vol12/issue4/ellison.html. 
Factbook (2005-2006). Quick facts about Murray State University, Fall 2005. Office of Institutional Research, Murray State University. Retrieved May 24, 2007 from http://www.murraystate.edu/oir/factbook2005.pdf

Furman, R., Collins, K., \& Swanson, J. (2003). Social work practice innovations: Helping Clients understand, explore, and develop their friendships. Advances in Social Work, 4(2), 116-129.

Golder, S., Wilkinson, D. M., \& Huberman, B. A. (2006). Rhythms of social interaction: Messaging within a massive online network. Retrieved December 21, 2006 from http://arxiv.org/PS_cache/cs/pdf/0611/0611137v1.pdf.

Gonchar, N., \& Adams, J. R. (2000). Living in cyberspace: Recognizing the importance of the virtual world in social work assessments. Journal of Social Work Education, 36(3), 587- 596.

Govani, T., \& Pashley, H. (2005). Student awareness of the privacy implications when using Facebook. Unpublished paper presented at "The Privacy Poster Fair" at the Carnegie Mellon University School of Library and Information Science. Retrieved December 21, 2006 from http://lorrie.cranor.org/courses/fa05/tubzhlp.pdf

Hale, C. J., Hannum, J. W., \& Espelage, D. L. (2005). Social support and physical health: The importance of belonging. Journal of American College Health, 53(6), 276-284.

Hargittai, E. (2007). Whose space? Differences among users and non-users of social network sites. Journal of Computer-Mediated Communication, 13(1), article 14. http://jcmc.indiana.edu/vol13/issue1/hargittai.html.

Hittner, J. B., \& Swickert, R. J. (2001). Modeling functional and structural social support via confirmatory factor analysis: Evidence for a second-order global support construct. Journal of Social Behavior and Personality, 16(1), 69-80.

Kaplowitz, M. D., Hadlock, T. D., \& Levine, R. (2004). A comparison of web and mail survey response rates. Public Opinion Quarterly, 68(1), 94-101.

Larose, S., \& Boivin, M. (1998). Attachment to parents, social support expectations and socioemotional adjustment during the high school-college transition. Journal of Research on Adolescence, 8(1), 1-27.

Lenhart, A., \& Madden, M. (2007).Social networking sites and teens: An overview. Pew Internet Project. Retrieved January 14, 2007 from http://www.pewinternet.org/pdfs/PIP_SNS_Data_Memo_Jan_2007.pdf.

Liu, H. (2007). Social network profiles as taste performances. Journal of ComputerMediated Communication, 13(1), article 13. Retrieved January 13, 2008 from http://jcmc.indiana.edu/vol13/issue1/liu.html.

Lorenzo, G., \& Dziuban, C. (2006).Ensuring the Net Generation is Net Savvy. In D. Oblinger (Ed.), Educause Learning Initiative-Advancing learning through IT innovation (pp. 1-19). Boulder, CO, EDUCAUSE. 
Mitrano, T. (2006). A wider world: Youth privacy and social networking technologies. Educause Review, 41(6), 16-28.

MacNeil, G., Stewart, J. C., \& Kaufman, A.V. (2000). Social support as a potential moderator of adolescent delinquent behaviors. Child and Adolescent Social Work Journal, 17(5), 361-379.

Menon, G. M., \& Miller-Cribbs, J. (2003). Online social work practice: Issues and guidelines for the profession. Advances in Social Work, 3(2), 104-116.

Myers, J. E., \& Mobley, A. K. (2004). Wellness of undergraduates: Comparisons of traditional and nontraditional students. Journal of College Counseling, 7(1), 40-49.

Oblinger, D. G., \& Hawkins, B. L. (2006). The myth about putting information online: "No one cares what you say online." Educause Review, 41(5), 14-15

Phinney, J. S., \& Haas, K. (2003). The process of coping among ethnic minority firstgeneration college freshmen: A narrative approach. The Journal of Social Psychology, 143(6), 707-726.

Sheehan, K. B. (2001). E-mail survey response rates: A review. Journal of ComputerMediated Communication, 6(2). [Online]: Available http://jcmc.indiana.edu/vol6/issue2/sheehan.html.

Subrahmanyam, K., \& Lin, G. (2007). Adolescents on the net: Internet use and wellbeing. Adolescence, 42(168), 659-667.

Waters, K., Harris, K., Hall, S., Nazir, N., \& Waigandt, A. (2006). Characteristics of social smoking among college students. Journal of American College Health, 55(3), 133-139.

Weckwerth, A. C., \& Flynn, D. M. (2006). Effect of sex on perceived support and burnout in university students. College Student Journal, 40(2), 237-249.

Weisz, C., \& Wood, L. F. (2000). Social identities and friendships: A longitudinal study of support for social identities. Journal of Social Behavior and Personality, 15(4), 441-458.

Wells, M. (2006). Internet-related problems coming to the attention of school social workers. Children \& Schools, 28(4), 237-242.

Wells, M., Mitchell, K. J., Finkelhor, D., \& Blease, K. B. (2006). Mental health professional's exposure to clients with problematic internet experiences. Journal of Technology in Human Services, 24(4), 35-52.

Wilcox, P., Winn, S., \& Fyvie-Gauld, M. (2005). 'It was nothing to do with the university, it was just the people': The role of social support in the first-year experience of higher education. Studies in Higher Education, 30(6), 707-722. 


\section{Author's note:}

Address correspondence to: Kala Chakradhar, Ph.D., 101S Applied Science Bldg., Murray State University, Murray, KY 42071. Email: kala.chakradhar@murraystate.edu. 